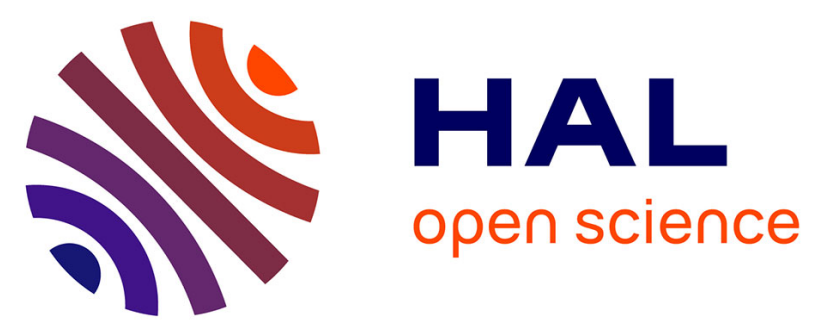

\title{
Coupling Supercapacitors and Aeroacoustic Energy Harvesting for Autonomous Wireless Sensing in Aeronautics Applications
}

Romain Monthéard, Marise Bafleur, Vincent Boitier, Xavier Dollat, Nicolas Nolhier, Estelle Piot, Christophe Airiau, Jean-Marie Dilhac

\section{To cite this version:}

Romain Monthéard, Marise Bafleur, Vincent Boitier, Xavier Dollat, Nicolas Nolhier, et al.. Coupling Supercapacitors and Aeroacoustic Energy Harvesting for Autonomous Wireless Sensing in Aeronautics Applications . Energy Harvesting and Systems, 2016, 3 (4), pp.265-276. 10.1515/ehs-2016-0003 . hal-01497529

\section{HAL Id: hal-01497529 \\ https://hal.science/hal-01497529}

Submitted on 28 Mar 2017

HAL is a multi-disciplinary open access archive for the deposit and dissemination of scientific research documents, whether they are published or not. The documents may come from teaching and research institutions in France or abroad, or from public or private research centers.
L'archive ouverte pluridisciplinaire HAL, est destinée au dépôt et à la diffusion de documents scientifiques de niveau recherche, publiés ou non, émanant des établissements d'enseignement et de recherche français ou étrangers, des laboratoires publics ou privés. 


\section{Coupling Supercapacitors and Aeroacoustic Energy Harvesting for Autonomous Wireless Sensing in Aeronautics Applications}

Romain Monthéard ${ }^{1}$, Marise Bafleur ${ }^{1}$, Senior Member, IEEE, Vincent Boitier ${ }^{1}$, Xavier Dollat ${ }^{1}$, Nicolas

Nolhier ${ }^{1}$, Estelle Piot ${ }^{2}$, Christophe Airiau ${ }^{3}$, Jean-Marie Dilhac ${ }^{1}$, Senior Member, IEEE

\footnotetext{
${ }^{1}$ LAAS-CNRS, Université de Toulouse, CNRS, UPS, INSA, Toulouse, France

${ }^{2}$ ONERA - The French Aerospace Lab, Toulouse, France

${ }^{3}$ IMFT, Université de Toulouse, Toulouse, France
}

Corresponding author: Marise Bafleur

Postal address: 7, av. Colonel Roche - BP52400-F-31031 Toulouse CEDEX4 FRANCE

Telephone: $+33(0) 561336966$

Fax: +33(0)561336208

Email: marise@laas.fr 
Abstract-This paper reports for the first time the experimental demonstration of a wireless sensor node only powered by an aeroacoustic energy-harvesting device, meant to be installed on an aircraft outside skin. Aeroacoustic noise is generated on purpose to serve as a means of converting mechanical energy from high velocity airflow into electrical energy. Results related to the physical characterization of the energy conversion process are presented. The proposed aeroacoustic transducer prototype, consisting in a rectangular cavity fitted with a piezoelectric membrane, is shown to deliver up to $2 \mathrm{~mW}$ AC power under Mach 0.5 airflow. Optimized power management electronics has been designed to interface with the transducer, including a self-powered Synchronized Switch Harvesting on Inductor (SSHI) interface circuit and an efficient buck-boost DC/DC converter. The design of micropower auxiliary circuits adds functionality while preserving high efficiency. This circuit stores energy in supercapacitors and is able to deliver a net output DC power close to $1 \mathrm{~mW}$. A fully autonomous system has been implemented and tested, successfully demonstrating aeroacoustic power generation by supplying a battery-free wireless datalogger in conditions representative of an actual flight.

Key words - energy harvesting, energy management, aeroacoustics, wireless sensor, embedded systems, battery-free, supercapacitors 


\section{Introduction}

In recent years, Wireless Sensor Networks (WSN) have been considered for various aeronautical applications, including flight tests during the development of a new aircraft and Structural Health Monitoring (SHM) during its commercial exploitation [1]. Up to now, this sensing is implemented using wires inducing kilometers of additional wiring (300 km extra cabling on an Airbus A380 for specific sensing during flight test in addition to the $500 \mathrm{~km}$ regular cabling). However, going wireless for communication also requires being wireless for energy. Isolated from the onboard electrical network, each sensor node needs to be self-powered. Environmental concerns, together with economical and safety-related issues, often prohibit the use of electrochemical batteries. Fortunately, energy may be harvested in the sensor's environment, providing a reliable and sustainable electrical power source.

The energy resource in an aircraft environment is diverse yet non-uniformly distributed, which leaves room for investigating various ambient energy harvesting techniques. Motivated by the opportunity to propose an alternative and complementary solution to those already under investigation (e.g. photovoltaics, vibrations, thermal gradients, etc...) [2] [3], the goal of this work is to exploit the abundant resource associated with the relative wind.

A very well known technique for generating electrical energy from airflow relies on the use of a wind turbine. Whereas such a device may be efficient at relatively large scale, its performance decays greatly with downscaling [4]. Therefore, alternative airflow energy harvesters have been proposed in recent years, following different approaches. One method, relying on the aeroelastic flutter phenomenon, consists in driving a membrane into vibration by directly submitting it to the airflow [5][6][7]. An alternative approach, based on the aeroacoustic phenomenon, implies that a membrane is driven into vibration by acoustic waves that result from the interaction of the airflow with a particular geometry. We consider that the latter approach leads to devices that are easier to realize and subject to less wear. A few contributions following this approach have been proposed recently. In [8], the authors proposed to use baffles so as to disturb the airflow in a pipe, thus generating acoustic noise. Using a nearby cavity, with depth and diameter of $7 \mathrm{~cm}$ each, and fitted with a pizeoelectric membrane, up to $0.55 \mathrm{~mW}$ electrical power was harnessed. Other authors employ a custom Helmholtz acoustic resonator, fitted with an electromagnetic [9] or a piezolectric [10] microgenerator. In [10], Matova et al. achieved $2 \mu \mathrm{W}$ at $13 \mathrm{~m} / \mathrm{s}$ airflow velocity, using a mesoscale prototype.

In this work, the aeroacoustic transduction process is investigated, with a focus on demonstrating the potential of such a technique to power a wireless sensor. Unlike earlier work, significantly higher airflow speeds are considered, as dictated by typical civil aircraft cruise speeds. These high speeds, and the necessity of minimizing the impact on the aerodynamic surfaces preclude the use of moving parts, or protruding devices such as miniaturized air turbines. Furthermore, this paper presents the design of optimized power management electronics and the experimental validation of a fully autonomous system.

In Section 2, after a brief introduction about the physics linked to aeroacoustic phenomenon, we describe the design and characterization results of the proposed transducer. Section 3 provides insights on the design of the power management electronic circuit as well as performance measurement. Finally, the full system evaluation is presented in Section 4.

\section{Device design and characterization}

\subsection{Proposed harvesting principle}

As mentioned in the introduction, in aeronautics application electrochemical storage is generally prohibited and energy harvesting coupled to electrostatic storage is a good alternative. Although many different sources of energy are present in an aircraft, for some parts of the aircraft far away from the engine, vibrations and thermal gradients are too low and solar energy is only available during daylight.

The originality of the proposed energy harvesting technique is to take advantage of the abundant 
resource associated with the relative wind of the aircraft. Instead of using a wind turbine that is not compatible with the aerodynamics of the aircraft, the basic idea is to locally generate aeroacoustic noise using a specifically designed cavity and the speed of the aircraft. To this aim, the contemplated transducer is made of a rectangular cavity fitted with a piezoelectric membrane at its bottom to harvest the aeroacoustic noise accordingly generated. The cavity is chosen as rectangular because aeroacoustic noise has been modelled for such a geometry (see \$2.2).

To cope with the intermittency of such generated energy, an electrostatic storage is needed as an energy buffer. Moreover, specific conversion architecture has to be designed to maximize the transfer of energy from the transducer on the one hand and to provide an efficient energy management on the other hand, since such architecture needs to autonomously start when the electrostatic storage is empty.

\subsection{Aeroacoustic transducer design}

The phenomenon of cavity noise is linked to self-sustained coherent oscillations in the shear layer developing above a cavity in the presence of grazing flow. A complex feedback process can lead to important radiated noise, with both discrete and broadband components [11]. Figure 1 depicts the basic geometry considered in this work that is a 2-D rectangular cavity with length $\mathrm{L}$ and depth $\mathrm{D}$ and presents a photograph of the corresponding fabricated harvester. As shown in Figure 1 (b), a screwed 2-mm thick flange is used to firmly attach the membrane, Murata $7 B B-20-6$, that is $20 \mathrm{~mm}$ in diameter and $420 \mu \mathrm{m}$ in thickness. Figure 2 shows typical generated acoustic spectra for different airflow speeds as obtained by the experimental apparatus described in Figure 3.

To size the cavity, we used Rossiter [11] and East [12] analytical formulations that respectively relate the peaks in the oscillation spectrum and the dominant frequency to the cavity dimensions:

$$
\begin{array}{cc}
f_{n}=\frac{U_{\infty}}{L} \frac{n-\alpha}{M+\frac{1}{\kappa}} & \text { Rossiter formula } \\
f_{1 / 4}=\frac{c_{0}}{4 D\left(1+0.65(L / D)^{0.75}\right)} & \text { East formula }
\end{array}
$$

In Rossiter formula, $U_{\infty}$ is the free-stream flow velocity, $L$ is the cavity length, $\alpha$ and $\kappa$ are empirical constants depending on the cavity aspect ratio (i.e. ratio between length $L$ and depth $D$ ), and $M$ is the free-stream Mach number, i.e. the ratio between the free-stream flow velocity and the speed of sound. $n$ is the index of Rossiter's mode. In East formula, $c_{0}$ is the speed of sound.

We used these formulas to design and test 6 different cavities with the constraint that they have to fit in the wind tunnel of the aeroacoustic test bench. This analytical approach provided a good correlation with experimental data [13]. The cavity with the respective dimensions: $30 \mathrm{~mm}$ width, $27 \mathrm{~mm}$ length and $27 \mathrm{~mm}$ depth, resulted in the highest aeroacoustic noise over a wider range of Mach numbers. The East and Rossiter formula can only predict the main resonance frequency of the noise emission as a function of the cavity geometry, but today the actual sound level can only be obtained experimentally. Some intensive Computational AeroAcoustics (CAA) simulations are currently in progress, especially based on Large Eddy Simulations (LES), but the computed acoustic level is always several $\mathrm{dB}$ under the measured one. It remains one of the main challenges of aeroacoustics and CAA research. Preliminary measurements reported in [13] showed that the dominant acoustic tone produced by this device is situated around $2300 \mathrm{~Hz}$, with a sound pressure level over $152 \mathrm{~dB}$, (Figure 2).

\subsection{Experimental setup}

Experiments have been performed in the aeroacoustic test bench "B2A wind tunnel" of ONERA Toulouse. This 4-meter long stainless steel tube of cross-section $50 \mathrm{~mm}$ x $50 \mathrm{~mm}$ is equipped with a quasi-anechoic 
outlet, to limit the amplitude of reflected acoustic waves (Figure 3). The transducer has been flush-mounted in the wind tunnel and submitted to a grazing flow ranging from Mach 0.3 up to Mach 0.6. The AC voltage has been measured in an open-circuit or across a variable resistor directly connected to the piezoelectric membrane.

\subsection{Voltage and power measurements}

The waveform of the open-circuit voltage across the piezoelectric membrane, resulting from this generated aeroacoustic noise for a Mach 0.5 airflow speed, exhibits a fairly clean sine shape, modulated by noise of much lower amplitude. The corresponding amplitude spectrum of Figure 4 (a) shows that the dominant tone is more than $60 \mathrm{~dB}$ over the next harmonic, and about $120 \mathrm{~dB}$ over the noise floor.

Figure 4 (b) shows the evolution of the RMS power dissipated in the load resistor with respect to the load value, for different airflow speeds. It can be seen that this energy harvester is able to deliver up to $2 \mathrm{~mW}$ AC power at Mach 0.5 , the corresponding voltage amplitude reaching 8 Volts. Furthermore, the optimal load resistor value (matched load) barely varies with respect to the airflow speed. Nevertheless, the maximum output power significantly depends on the airflow speed.

So as to understand the dominant effects regarding the electrical power generation, we have summarized in Table 1 the acoustic data in the wind tunnel and the corresponding electrical power generated by the piezoelectric membrane. To obtain these data, we measured the sound level by implementing a microphone on the upper wall of the wind tunnel facing the cavity and computed the acoustic power from these experimental data by doing the approximation of a plane wave and using as a reference section the top section of the cavity (30 mm*27 $\mathrm{mm}$ ). As a result, the ratio $\mathrm{P}_{\text {elec }} / \mathrm{P}_{\mathrm{ac}}$ cannot be considered as the actual transduction efficiency. From these data, it can be first noticed that the frequency of the sound peak level (SPL) is almost the same whatever the Mach number. Secondly, the generated electrical power perfectly scales with the maximum sound peak level. We can then conclude that the most important and dominant parameter is the acoustic noise level. It has to be mentioned that this experiment does not exactly reproduce the conditions of the targeted application since in this case the cavity will be in open-air configuration.

\section{Power management electronics}

\subsection{Architecture}

The power management circuit interfaces the piezoelectric membrane with the wireless sensor node. It comprises two main stages, an AC/DC converter and a DC/DC converter, followed by storage supercapacitors as well as regulation and protection circuitry, as depicted in Figure 5.

When designing this power management circuit, our main objectives were firstly to maximize the extracted power and secondly, to optimize the efficiency of the circuit. Another challenge of this circuit is then to provide a regulated voltage only using supercapacitors as storage device while minimizing power consumption. Each stage of the proposed power management circuit is described in the following subsections.

\subsection{AC/DC converter}

The first stage is used to rectify the AC voltage generated by the piezoelectric membrane. Reviews in piezoelectric power conditioning circuits highlight the performance of the SSHI interface (Synchronized Switch Harvesting on Inductor) [14][15], especially for pseudo-sinusoidal excitations. In particular, it has been shown that such an interface circuit, which introduces a nonlinear behavior to the energy conversion process, yields a significant improvement in terms of extracted power. In this work, a self-powered parallel SSHI circuit has been implemented. As described in [16], the parallel SSHI interface circuit consists in connecting an inductor $\mathrm{L}_{\mathrm{p}}$ and a switch in parallel with a piezoelectric element. As the membrane displacement reaches an extremum, which translates to a zero current flow, the switch is turned on for a short time. The connection of the inductor with the 
intrinsic capacitance $\mathrm{C}_{0}$ of the piezoelectric element form a resonant LC network, which yields a voltage inversion so that voltage and current are set back in phase. Ideally, the switch should be on during half the LC network pseudo-period, expressed as:

$$
T_{L C} / 2=\pi \sqrt{ } L_{p} C_{0}
$$

The schematic given in Figure 6 (a) describes how the parallel SSHI interface has been implemented. In particular, it is shown that the switch used to connect the inductor to the piezoelectric element is made of two selfpowered unipolar electronic breakers, as proposed in [17].

\section{i. $\quad$ Inductor sizing}

Two main conflicting constraints apply to the inductor sizing. First, the inductance value $\mathrm{L}_{\mathrm{p}}$ must be small enough to make the period $\mathrm{T}_{\mathrm{LC}}$ much smaller than the membrane vibration period. Secondly, the shorter $\mathrm{T}_{\mathrm{LC}}$, the shorter the switching process must be. As a consequence, this raises a constraint on how fast the switching circuit must operate. This latter constraint is especially strong as the membrane vibration frequency is high. In literature, the SSHI technique is commonly applied to low-frequency vibrating systems (a few tens Hz [18][19][20]). However, its application to higher frequency systems (here, a few thousands Hz) raises sizing constraints that are rarely discussed. More precisely, a practical SSHI implementation implies non-ideal switching events, affected by incompressible delays due, for example, to lag in the voltage extremum detection process. The negative impact of these delays on performance decreases as the period $\mathrm{T}_{\mathrm{LC}}$ increases. Therefore, the inductor value cannot be chosen arbitrarily big nor small. In this work, a value $\mathrm{L}_{\mathrm{p}}=1 \mathrm{mH}$ has been selected to satisfy both constraints. Given an excitation frequency $\mathrm{f}=2200 \mathrm{~Hz}$ and a capacitance $\mathrm{C}_{0}=9 \mathrm{nF}$, this value leads to a ratio of 50 between $\mathrm{T}_{\mathrm{LC}}$ and the piezoelectric membrane vibration period.

\section{ii. Switch implementation}

The breaker switch has been implemented using two self-powered unipolar electronic breakers, as illustrated in Figure 6 (b), and proposed by the authors of this technique [17]. However, two modifications have been introduced compared to the original proposed version. Firstly, the main bipolar transistor has been replaced by a MOSFET, as suggested in [19] [21], in order to reduce the amount of energy needed for each switching. Thus, resistor $R_{4}$ has been added to discharge the gate of transistor $M_{1}$. Secondly, the passive network composed of $R_{3}-C_{2}$ has been added, protecting the MOSFET gate against possible overvoltage conditions. Indeed, this network acts as a high-pass filter through which only the pulse part of the gate control signal spans, whereas the slower components in this signal are highly attenuated. Thereby, carefully selecting the value of these components allows a significant reduction of the peak voltage applied to transistor $\mathrm{M}_{1}$ while improving its dynamic behavior (details are given in [22]). In particular, the value of $\mathrm{C}_{2}$ sets boundaries on the input AC voltage range that may be applied to the SSHI stage.

The circuit has been realized using discrete components whose values are given in Table 2 . Under a purely sinusoidal excitation at $2230 \mathrm{~Hz}$, this circuit improves power extraction by a factor of 3 to 5 compared to a standard diode bridge rectifier. When applied to the aeroacoustic transducer mounted in the wind tunnel, it has been experimentally verified that the proposed SSHI circuit allows doubling the output power (see Figure 11 hereafter). However, this circuit also yields a fourfold increase of the effective output impedance. Generally speaking, this translates to superior constraints regarding the design of the DC/DC converter, as detailed in the following subsection. In particular, it implies to deal with higher voltages, which may be favorable in conditions where the piezoelectric membrane naturally generates low voltages. Nevertheless, this may be disadvantageous if the voltage at the output of the SSHI circuit reaches high values, as it raises requirements when selecting the components for the DC/DC converter as well as for the SSHI stage itself. For instance, these requirements may include capacitors, diodes and transistors breakdown voltages, as well as operating voltage ranges of integrated circuits. 


\subsection{DC/DC converter}

\section{i. Input impedance}

The input impedance of the DC/DC converter must be controlled so as to match the output impedance of the preceding stage, in order to achieve maximum power transfer from the energy harvester. As stated previously, the optimal load varies very little with the airflow speed, which allows using a fixed input impedance topology. Therefore, it has been chosen to implement a buck-boost converter operating in discontinuous conduction mode, as proposed in [23][24][25].

The DC/DC converter has been designed to deal with an input power in the milliwatt range and to achieve an input impedance of some tens of $\mathrm{k} \Omega$. Figure 7 (a) shows the schematic of the proposed buck-boost converter and Table 3 provides the components values. A low-power oscillator is used to drive $\mathrm{M}_{1}$ switch. Whereas in [25] the oscillator is powered by the battery connected at the output, in this case it is connected at the input and must be self-starting, since the output is used to charge supercapacitors and therefore $\mathrm{V}_{\text {out }}$ is 0 volts at startup. A very low quiescent current LDO regulator (Texas Instruments TPS70925) connected at the converter input pins provides a stable $2.5 \mathrm{~V}$ power supply $\left(\mathrm{V}_{\mathrm{LDO}}\right)$ to the oscillator circuit. Although this solution causes additional power loss, it avoids undesirable deviations of the oscillator characteristics caused by input voltage variations. Moreover, it protects the oscillator circuit from overvoltage on its supply pins.

In this configuration, the input impedance $Z_{\text {in }}$ can be made independent of the output current, such that:

$$
Z_{\text {in }}=\frac{2 L f_{s}}{\delta^{2}}
$$

where $f_{s}$ is the switching frequency, $L$ the inductor value and $\delta$ is the duty cycle.

| Considering the expression of the input impedance given by equation (4), the selection of a rather large inductance allows relaxing the constraints regarding the ratio $\mathrm{f}_{s} / \delta^{2}$, which governs the oscillator speed. As a consequence, it reduces the power overhead required to drive the switch, thus maximizing the converter overall efficiency.

\section{ii. Oscillator circuit}

The control signal $\left(\mathrm{V}_{\mathrm{cmd}}\right)$ applied to the gate of transistor $\mathrm{M} 1$ is generated by an oscillator based on an astable comparator circuit, as shown in Figure 7 (b). Such a topology allows adjusting the duty cycle while consuming very low power, as long as the oscillation frequency is kept low. The duty cycle (thus, the converter input impedance) can be controlled through the potentiometer $r$. Power consumption has been minimized by using a comparator circuit with very low quiescent current $\left(\mathrm{I}_{\mathrm{Q}}=0.8 \mu \mathrm{A}\right.$ typ. $)$, yet sufficiently short propagation delays $\left(\mathrm{t}_{\mathrm{p}}=6\right.$ $\mu \mathrm{s})$. The latter feature is desirable to achieve very low duty cycle, and then to increase the maximum achievable input impedance. Finally, the diode D being blocked most of the time, it has been chosen with low reverse current.

Assuming $\mathrm{r} \ll<\mathrm{R}$, the oscillating frequency $\mathrm{f}_{\mathrm{s}}$ and the duty cycle $\delta$ are expressed according to the following equations:

$$
\begin{gathered}
f_{s} \approx \frac{1}{R C \ln (2)} \\
\delta \approx \frac{r}{R}
\end{gathered}
$$

Experimental testing led to several adjustments in the oscillator design, which has been eventually set to oscillate at about $400 \mathrm{~Hz}$, while its current consumption is below $12 \mu \mathrm{A}$.

\section{iii. Efficiency}

The DC/DC converter has been characterized using the test circuit shown in Figure 8 (a). Input and output capacitors are set to $10 \mu \mathrm{F}$. Efficiency has been evaluated under various source parameters in terms of input 
voltage $\left(\mathrm{V}_{\mathrm{in}, \mathrm{cc}}\right)$ and input resistance $\left(\mathrm{R}_{\mathrm{in}}\right)$, whereas the load connected to the output has been swept over a wide range of values. The graph of Figure 8 (b) shows measurement results of the converter efficiency for an identical output power of $1 \mathrm{~mW}$, yet with varying input conditions. Efficiency reaches up to $83 \%$ and is over $70 \%$ over a wide range of load currents. It is worth mentioning that for a maximum output power around $200 \mu \mathrm{W}$, the efficiency is around $70 \%$ over one decade of load currents.

\subsection{Energy storage and additional circuitry}

The output of the DC/DC converter is connected to an energy storage stage as well as additional protection circuitry, as described in Figure 9 (a).

\section{i. $\quad$ Supercapacitors}

The energy storage stage consists in two series-connected $0.5 \mathrm{~F}$ supercapacitors, so as to withstand the 5 Volts output regulated voltage. It has been sized to provide the load, namely a data logger, with the transient energy $(0.5 \mathrm{~J})$ needed for the initial radio communication. It also includes a charge balancing circuit consuming less than $0.5 \mu \mathrm{A}$.

\section{ii. Overvoltage protection (OVLO)}

A simple hysteresis comparator circuit is used to protect the energy storage unit against overvoltage. It is based on a low-power commercial IC (Linear Technology LTC1540, IQ $=0.3 \mu \mathrm{A}$ ) that provides its own reference voltage (Vref $=1.182 \mathrm{~V})$ and consumes less than $1 \mu \mathrm{A}$. When the supercapacitor charge voltage reaches the value of $5 \mathrm{~V}$ (maximum operating voltage), the output of the comparator triggers on a MOS transistor that will discharge, via a resistor, the supercapacitor until reaching the low threshold voltage value of $4.9 \mathrm{~V}$.

\section{iii. Undervoltage lock out (UVLO)}

The last stage of the energy management circuit is used to isolate the energy storage unit from the load until it reaches a sufficient voltage to properly feed that load. This function is necessary to avoid overrated current consumption caused by insufficient supply voltage, which may even cause startup failure [27]. It is also implemented with a hysteresis comparator, based on an even lower quiescent current IC (Texas Instruments TLV3691, IQ=75 nA) so as to further minimize power consumption.

The total current consumption of all additional output circuitry is plotted on Figure 9 (b), as a function of the output voltage. It can be seen that it never exceeds $2.5 \mu \mathrm{A}$ over the $0-5 \mathrm{~V}$ range, which is a good performance given the fact that these circuits are built using discrete off-the-shelf components.

\section{iv. Ultra low-power hysteresis comparators}

Here the authors would like to highlight a means to reduce the power consumption associated with the hysteresis comparator, which can be found as a subcircuit in many usual electronic functions. In the "classical" implementation shown in Figure 10 (a), the feedback resistor $R_{3}$ is typically much larger than $R_{1}$ and $R_{2}$, especially when the hysteresis window is narrow. The maximum static current consumption, excluding that of the active circuit, is given by:

$$
I_{s}=\frac{V_{i n \text { max }}}{R_{1}+R_{2}}
$$

Minimizing the current consumption typically requires setting $\mathrm{R}_{3}$ as high as possible, then determining $\mathrm{R}_{1}$ and $\mathrm{R}_{2}$ according to the target threshold levels. Let us consider the case of the OVLO circuit presented above, whose thresholds are defined as $\mathrm{V}_{\mathrm{H}}=5.0 \mathrm{~V}$ and $\mathrm{V}_{\mathrm{L}}=4.9 \mathrm{~V}$. Using the schematic of Figure 10 (a) and setting $\mathrm{R}_{3}=22$ $M \Omega$, one finds $R_{1}=440 \mathrm{k} \Omega$ and $\mathrm{R} 2=132 \mathrm{k} \Omega$, which yields, assuming Vin,max $=5.0 \mathrm{~V}$, a static current $\mathrm{I}_{\mathrm{s} 1}=8.7 \mu \mathrm{A}$. Such a current value cannot be seen as negligible in a system dealing with power in the milliwatt range. Figure 
10 (b) shows the schematic of an alternative solution that makes use of an additional MOSFET transistor, but does not require a feedback resistor. Following the given specifications, the highest resistance is now $R_{1}=22 \mathrm{M} \Omega$, while $\mathrm{R}_{2}=6.8 \mathrm{M} \Omega$ and $\mathrm{R}_{2 \mathrm{~b}}=187 \mathrm{k} \Omega$. In this configuration, the static current is given by $\mathrm{I}_{\mathrm{s} 2}=0.17 \mu \mathrm{A}$, that is 50 times lower for the same function, at the cost of one extra transistor. This obviously helps preserve the overall efficiency, especially in very low power management systems.

\subsection{Characterization}

Experiments have been carried out to validate the positive impact of each stage, at an airflow speed of Mach 0.5. Figure 11 illustrates the obtained output power using different circuit configurations (auxiliary output circuitry, i.e. OVLO, UVLO, and the supercapacitor balancing circuit, are not included). It confirms the significant improvement brought by the combination of the SSHI interface plus the DC/DC converter, compared to the standard, diode bridge rectifier interface. The implementation of the SSHI stage allows doubling the maximum power from $0.56 \mathrm{~mW}$ to $1.12 \mathrm{~mW}$ and the optimum load resistance evolves from $10 \mathrm{k} \Omega$ to $36 \mathrm{k} \Omega$, compared to a standard rectifier circuit. Introducing a DC-DC converter, despite some power losses (16\% at maximum), has the advantage to make the efficiency of the system almost independent of the load resistance. The maximum efficiency of this DC-DC converter is $87.3 \%$ and is above $70 \%$ over the typical range of loads and input sources of the application. When combining the SSHI and the DC-DC converter stages, the maximum output power reaches $0.87 \mathrm{~mW}$ (i.e. $55 \%$ improvement compared to a standard rectifier circuit) and the output power is much less dependent on the load resistance. A picture of the realized printed circuit board is shown on Figure 12. The two bulky inductors are protruding, whereas the two supercapacitors are very thin and have been soldered on the rear side of the board.

\section{Full system experimental validation}

The full system, as depicted in Figure 5, comprises the aeroacoustic transducer, the AC/DC converter with the SSHI interface, the buck-boost DC/DC converter in discontinuous conduction mode, connected to the supercapacitors storage and output protection circuits. It has been used as a power supply for a wireless sensor node based on Jennic JN5148 microcontroller [26].

The wireless sensor node used in this work is essentially a datalogger featuring an IEEE802.15.4 radio interface. It has been programmed to sense its internal temperature and to send it over the radio link once every 6 seconds to a coordinator module linked to a PC. Its power stage includes an LDO regulator that draws a $0.5 \mu \mathrm{A}$ quiescent current and delivers a $3.3 \mathrm{~V}$ regulated voltage. At startup, the datalogger initializes the radio communication with the coordinator, which translates to an energy consumption of $0.5 \mathrm{~J}$. Then, it enters sleep mode and wakes up once every 6 seconds to perform a new measurement and wirelessly transmit the result. Each senseand-transmit phase results in an energy consumption of $1 \mathrm{~mJ}$, whereas the sleep current is about $4.4 \mu \mathrm{A}$. Apart from the startup phase, this datalogger consumes an average power of $181 \mu \mathrm{W}$.

Figure 13 shows the experimental test bench and the evolution of the power management circuit output voltage, which powers the datalogger. The UVLO circuit has been set to enable the output when the voltage across the supercapacitors reaches about 3.9 V. Initially fully discharged, the system initializes within 42 minutes. From that instant on, the coordinator module starts receiving temperature data, which is then displayed in a terminal window. A video recording of this experiment can be watched at the following website address: http://youtu.be/1kkq-5g9D_g. Because of the $0.5 \mathrm{~J}$ energy consumption at activation, a large capacitance and therefore a long charging time is needed. Actually, the capacitance value is here oversized to power the Jennic module and could be used with systems exhibiting higher power surge. After a successful startup, the datalogger is running while the storage supercapacitors keep on charging. As the output voltage reaches its maximum value, the system enters regulation. The average charging power is about $0.8 \mathrm{~mW}$. 
To greatly improve the datalogger activation time and optimize energy usage, an interesting solution would be to implement an adaptive storage strategy [28]. The basic principle is based on the use of a (super-) capacitors matrix, which arranges itself according to the global amount of energy stored. This structure shifts from an all-series to an all-parallel arrangement with discrete intermediate steps, the cycle being reversible whatever the current state. The all-series arrangement is used when the storage is empty and allows rapidly reaching the voltage threshold for proper operation and the all-parallel one helps maximize the stored energy. Such an approach, in addition to providing an earlier start-up of the wireless system, also permits a better usage of the stored energy and as a result an autonomy improvement.

\section{Conclusion and perspectives}

In this work, we have demonstrated the feasibility of a realistic, fully standalone system, made energyautonomous by means of aeroacoustic energy generation. Based on a simple rectangular cavity fitted with a piezoelectric membrane, the proposed solution achieves the conversion of kinetic energy provided by an airflow using aeroacoustic transduction. In this paper, the generation of electrical power in the milliwatt range is demonstrated, which makes such a device suitable for powering autonomous wireless sensor nodes. In particular, the prototype introduced in this paper generates up to $2 \mathrm{~mW}$ AC power at Mach 0.5 airflow. Custom energy management circuitry has been designed to efficiently deal with the generated power. The implementation of a selfpowered parallel SSHI converter significantly improves power generation under a non-ideal, relatively high frequency excitation signal. Combining it with a DC/DC converter makes it possible to manage, regulate and store the produced energy with $55 \%$ improvement in term of peak harvested energy compared to a standard rectifier circuit.

The demonstration of aeroacoustic energy harvesting associated with a complete battery-free energy management circuit constitutes an original contribution, especially in the aeronautic context. This method could be applied when other ambient energy sources (light, heat, vibrations) are weak or absent, such as for the monitoring of landing gear key parameters (for health monitoring), when landing gears are deployed during final descent and landing (hard landing monitoring). In that circumstances, adding cavities would not raise strong issues, while aircraft speed would be in the range explored in this paper. Such an application could be considered for powering loads in the microwatt range, therefore requiring reduced storage capabilities and consequently much smaller startup time. Future work will focus on refining the transducer design so as to improve its effectiveness over a wider range of airflow speeds, as well as designing a micro-scale prototype.

\section{Acknowledgement}

This work has been partially funded by the Direction Générale de l'Armement (DGA) and by the French program "Investissements d'Avenir" within the framework of CORALIE project.

\section{References}

[1] J.-M. Dilhac, M. Bafleur, J.-Y. Fourniols, C. Escriba, R. Plana, D. Dragomirescu, L. Assouère, P. Pons, H. Aubert, and C. Buchheit, "Cross-functional design of wireless sensor networks applied to aircraft health monitoring," in Proc. International Workshop on Structural Health Monitoring, Stanford, USA, 2009.

[2] J.-M. Dilhac and M. Bafleur, "Energy harvesting in aeronautics for battery-free wireless sensor networks," IEEE Aerospace and Electronic Systems Magazine, vol. 29, pp. 18-22, Aug. 2014.

[3] C. Vanhecke, L. Assouère, A. Wang, P. Durand-Estèbe, F. Caignet, J.M. Dilhac, M. Bafleur, "Multisource and Battery-free Energy Harvesting Architecture for Aeronautics Applications", IEEE Transactions on Power Electronics, 2015, vol.30, nº, pp 3215-3227.

[4] P. Mitcheson, E. Yeatman, G. Rao, A. Holmes, and T. Green, "Energy harvesting from human and machine motion for wireless electronic devices," Proceedings of the IEEE, vol. 96, pp. 1457-1486, Sept. 2008.

[5] S. Li, J. Yuan, and H. Lipson, "Ambient wind energy harvesting using cross-flow fluttering," Journal of Applied Physics, vol. 109, Jan. 2011.

[6] Humdinger wind energy, www.humdingerwind.com 
[7] C. A. K. Kwuimy, G. Litak, M. Borowiec, and C. Nataraj, "Performance of a piezoelectric energy harvester driven by air flow," Applied Physics Letters, vol. 100, Jan. 2012.

[8] R. Hernandez, S. Jung, and K. I. Matveev, "Acoustic energy harvesting from vortex-induced tonal sound in a baffled pipe," in Proceedings of the Institution of Mechanical Engineers, Part C: Journal of Mechanical Engineering Science, SAGE, Jun. 2011.

[9] S.-H. Kim, C.-H. Ji, P. Galle, F. Herrault, X. Wu, J.-H. Lee, C.-A. Choi, and M. G. Allen, "An electromagnetic energy scavenger from direct airflow," Journal of Micromechanics and Microengineering, vol. 19, nº 9, p. 094010, 2009.

[10] S. Matova, R. Elfrink, R. Vullers, and R. van Schaijk, "Harvesting energy from airflow with micromachined piezoelectric harvester inside a helmholtz resonator," in Proceedings of PowerMEMS 2010, (Leuven, Belgium), Nov. - Dec. 2010.

[11] C. W. Rowley and D. R. Williams, "Dynamics and control of high-reynolds-number flow over open cavities," Annual Reviews of Fluid Mechanics, vol. 38, pp. 251-276, Jan. 2006.

[12] L. East, “Aerodynamically induced resonance in rectangular cavities," Journal of Sound and Vibration, vol. 3, pp. $277-287$, May 1966.

[13] R. Monthéard, S. Carbonne, M. Bafleur, V. Boitier, J.-M. Dilhac, X. Dollat, N. Nolhier, E. Piot, and C. Airiau, "Proof of concept of energy harvesting from aero acoustic noise," in Proceedings of PowerMEMS 2012, Atlanta, USA, Dec. 2012.

[14] D. Guyomar and M. Lallart, "Recent progress in piezoelectric conversion and energy harvesting using nonlinear electronic interfaces and issues in small scale implementation," Micromachines, vol. 2, pp. 274-294, 2011.

[15] G. D. Szarka, B. H. Stark, and S. G. Burrow, "Review of power conditioning for kinetic energy harvesting systems," IEEE Transactions on Power Electronics, vol. 27, pp. 803-815, Feb. 2012.

[16] D. Guyomar, Y. Jayet, L. Petit, E. Lefeuvre, T. Monnier, C. Richard, and M. Lallart, "Synchronized switch harvesting applied to self powered smart systems: Piezoactive microgenerators for autonomous wireless transmitters," Sensors and Actuators A: Physical, vol. 138, pp. 151-160, Jul. 2007.

[17] M. Lallart, E. Lefeuvre, C. Richard, and D. Guyomar, "Self-powered circuit for broadband, multimodal piezoelectric vibration control," Sensors and Actuators A: Physical, vol. 143, pp. 377-382, 2008.

[18] J. Liang and W.-H. Liao, "An improved self-powered switching interface for piezoelectric energy harvesting," in IEEE International Conference on Information and Automation, pp. 945-950, 2009.

[19] L. Mateu, L. Luhmann, H. Zessin, and P. Spies, "Modified parallel SSHI AC-DC converter for piezoelectric energy harvesting power supplies," in Telecommunications Energy Conference (INTELEC), 2011 IEEE 33rd International, pp. 1-7, Oct. 2011.

[20] Y.-Y. Chen, D. Vasic, F. Costa, W.-J. Wu, and C.-K. Lee, "A self-powered switching circuit for piezoelectric energy harvesting with velocity control," European Physical Journal of Applied Physics, vol. 57, mar. 2012.

[21] M. Lallart and D. J. Inman, "Low-cost integrable tuning-free converter for piezoelectric energy harvesting optimization," IEEE Transactions on Power Electronics, vol. 25, pp. 1811-1819, July 2010.

[22] R. Monthéard, Récupération d'énergie aéroacoustique et thermique pour capteurs sans fil embarqués sur avion. PhD thesis, Université de Toulouse (France), Nov. 2014.

[23] A. Kasyap, J. Lim, K. Ngo, A. Kurdila, T. Nishida, M. Sheplak, and L. Cattafesta, "Energy reclamation from a vibrating piezoceramic composite beam," in Proc. 9th International Congress on Sound and Vibration, no. 271, Orlando, USA, Jul. 2002.

[24] E. Lefeuvre, D. Audigier, C. Richard, and D. Guyomar, "Buck-boost converter for sensorless power opti- mization of piezoelectric energy harvester," IEEE Transactions on Power Electronics, vol. 22, pp. 2018- 2025, Sept. 2007.

[25] N. Kong, D. S. Ha, A. Erturk, and D. J. Inman, "Resistive impedance matching circuit for piezoelectric energy harvesting," Journal of Intelligent Materials Systems and Structures, vol. 21, pp. 1293-1302, Sept. 2010.

[26] R. Monthéard, C. Airiau, M. Bafleur, V. Boitier, J.-M. Dilhac, X. Dollat, N. Nolhier, and E. Piot, "Powering a commercial datalogger by energy harvesting from generated aeroacoustic noise," Journal of Physics: Conference Series, vol. 557, Nov. 2014

[27] V. Boitier, P. Durand Estèbe, R. Monthéard, M. Bafleur, and J.-M. Dilhac, "Under voltage lock-out design rules for proper start-up of energy autonomous systems powered by supercapacitors," Journal of Physics: Conference Series, vol. 476, no. 012121, 2013.

[28] R. Monthéard, M. Bafleur, V. Boitier, J-M. Dilhac and X. Lafontan, "Self-adaptive switched ultra-capacitors: a new concept for efficient energy harvesting and storage", in Proc. POWERMEMS 2012, Atlanta (USA), December 2-5, 2012. 


\section{FIGURE CAPTIONS}

Figure 1. Proposed aeroacoustic transducer: schematic of a rectangular cavity of length $L$ and depth $D$ (a) and fabricated aeroacoustic energy harvester with the piezoelectric membrane at its bottom (b).

Figure 2. Generated acoustic spectra at different airflow speeds (Mach 0.3 to Mach 0.5).

Figure 3. Diagram of the experimental aeroacoustic test bench.

Figure 4. Aeroacoustic measurement data for the cavity under study: amplitude spectrum of the open-circuit voltage under Mach 0.4 airflow (a) and RMS output power dissipated versus load resistor, for different airflow speeds (b).

Figure 5. General architecture of the power management circuit.

Figure 6. Schematic of the AC/DC converter (a) and of the positive side electronic breaker (b).

Figure 7. Schematic of the buck-boost converter (a) and of the astable oscillator (b).

Figure 8. Measurement of the DC/DC converter efficiency: implemented test circuit (a) and efficiency plot under various load and input conditions with identical output power (b). The corresponding maximum output power is around $1 \mathrm{~mW}$.

Figure 9. Schematic of the output stages (a) and current consumption of DC/DC converter output circuitry (b).

Figure 10. Two implementations of a discrete hysteresis comparator circuit: with feedback resistor (a) and without feedback resistor.

Figure 11. Comparison of the obtained output power according to the conversion strategy at an airflow speed of Mach 0.5 . Auxiliary circuitry (OVLO, UVLO and supercapacitor balancing circuit) is not included.

Figure 12. Top and bottom views of the printed circuit board.

Figure 13. Photograph of the experimental implementation of the wireless sensing system powered by the aeroacoustic transducer in the wind tunnel (a) and measured output voltage of the proposed power management circuit that powers the data logger (b). 


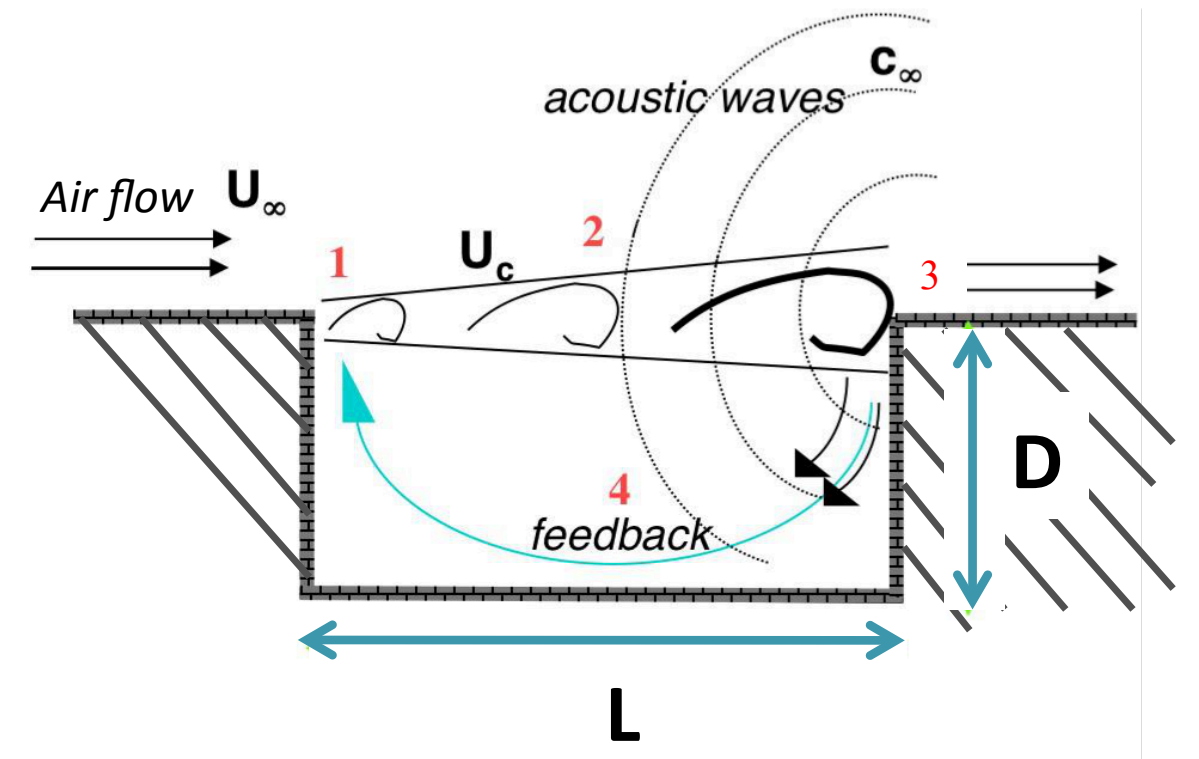

Figure 1 (a) 


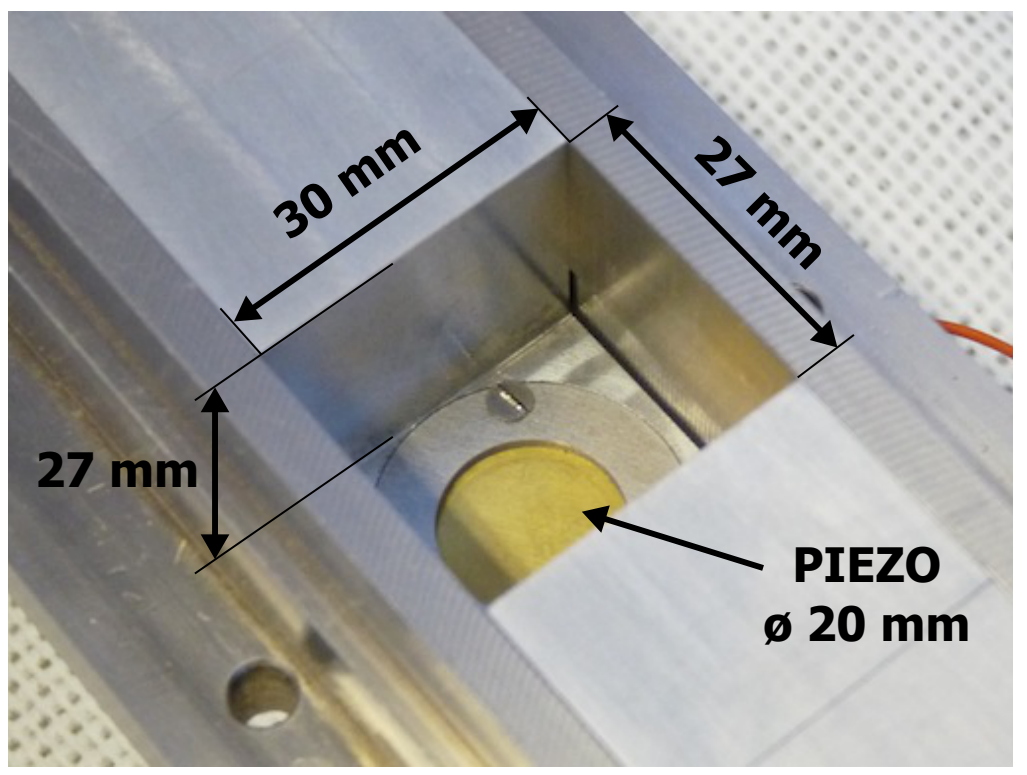

Figure 1 (b) 


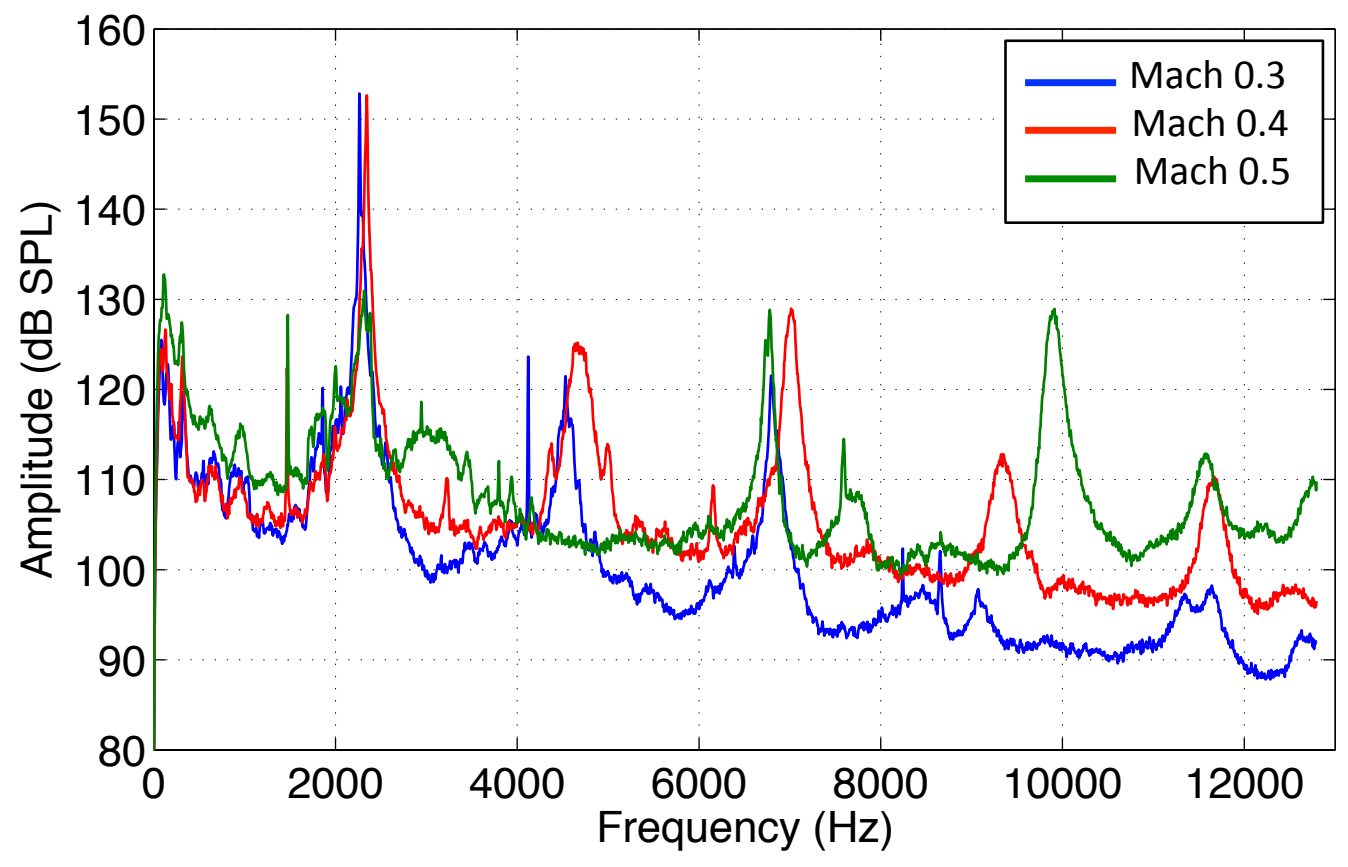

Figure 2 


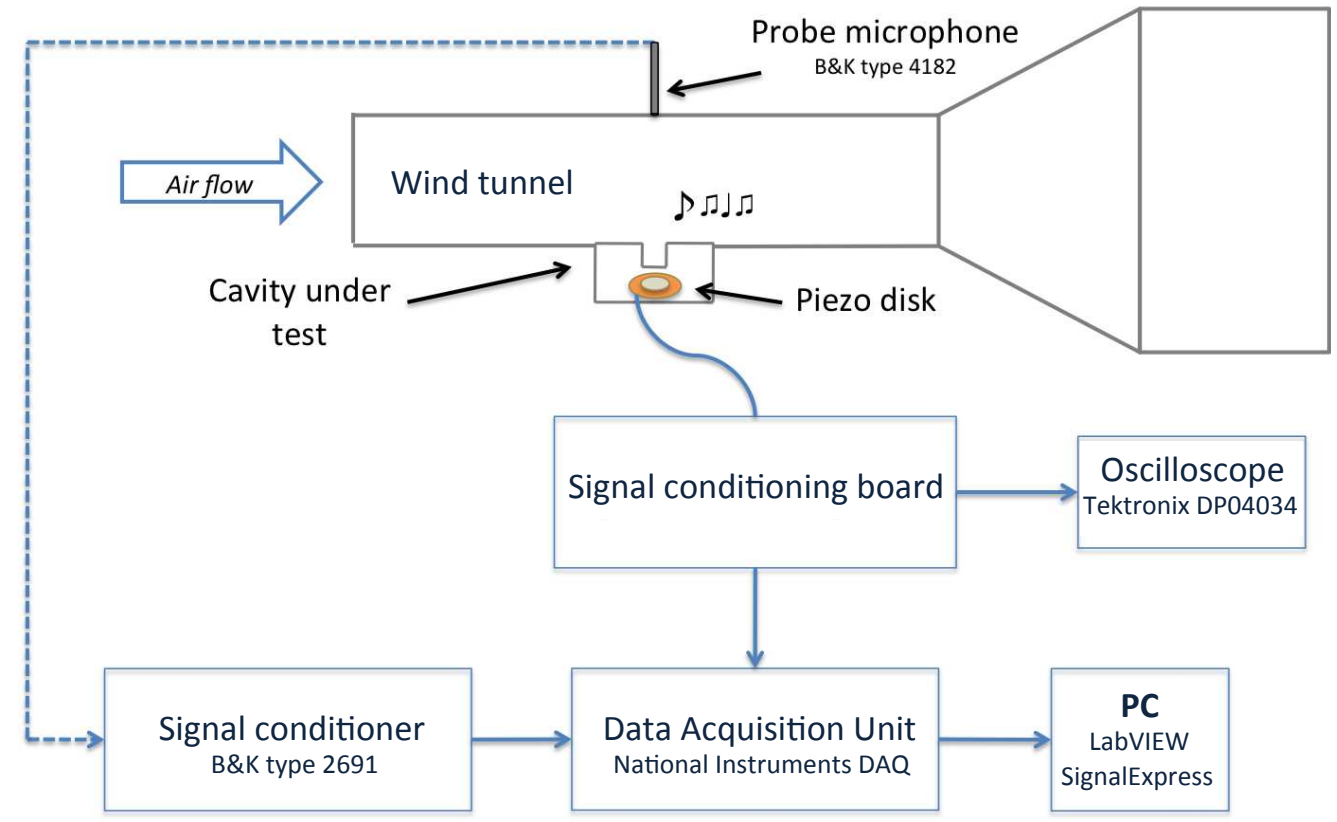

Figure 3 


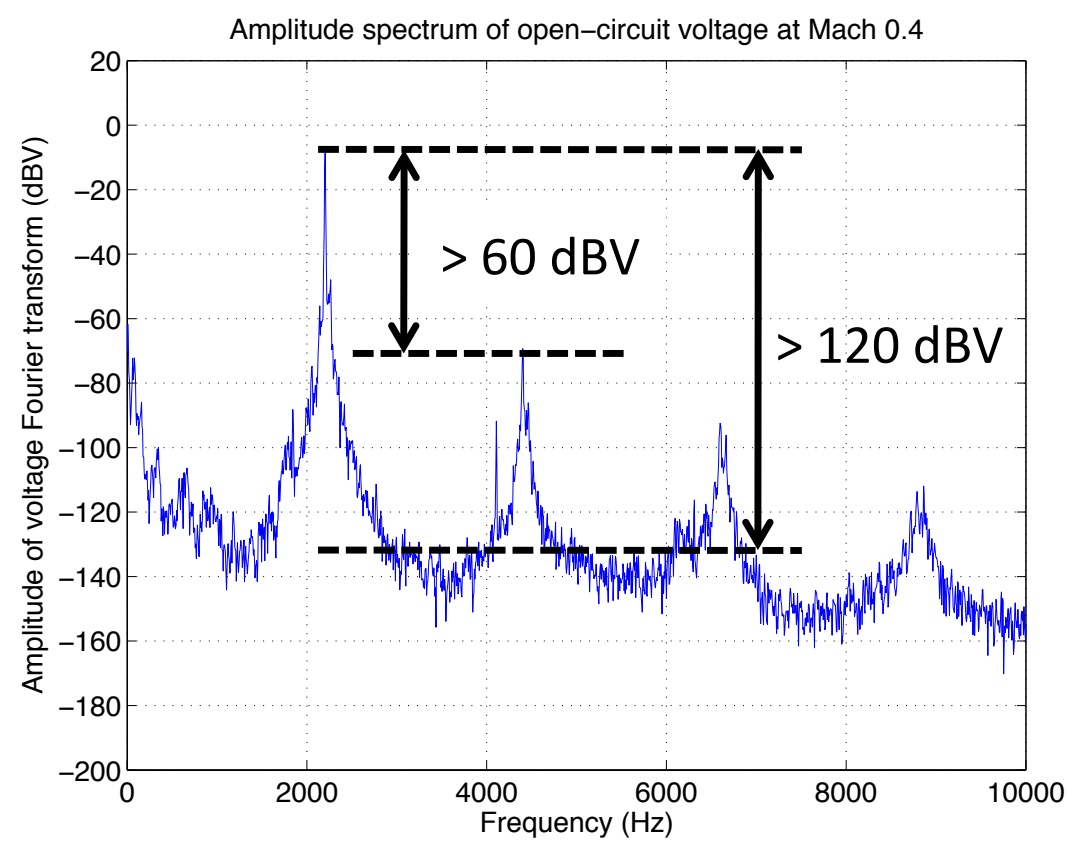

Figure 4 (a) 


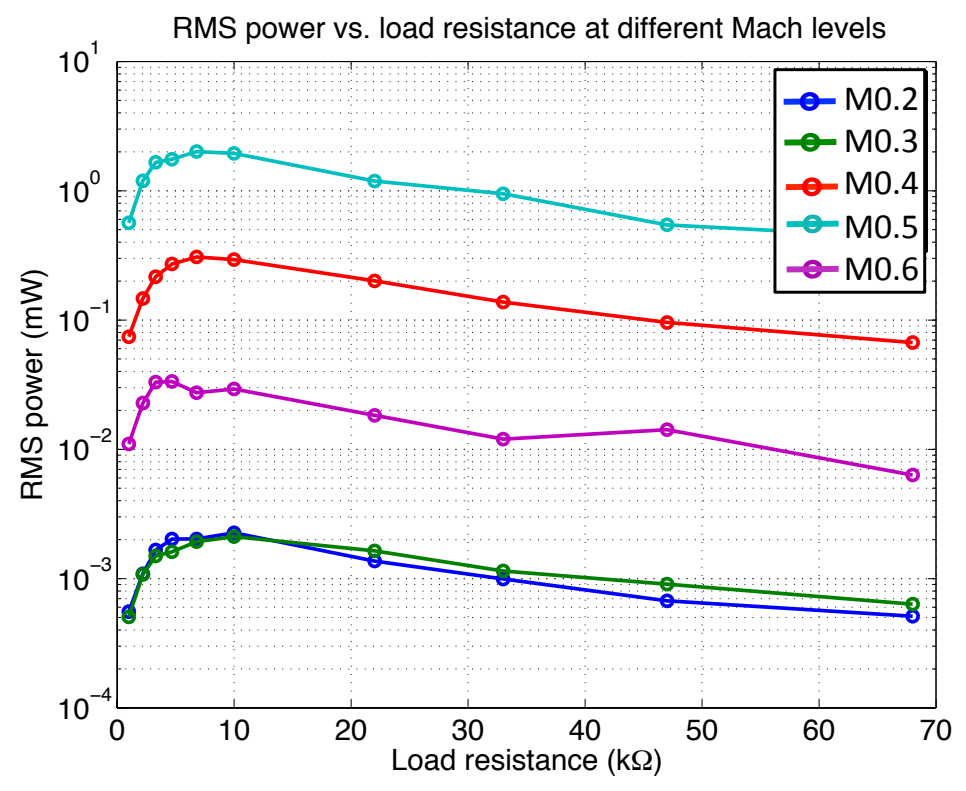

Figure 4 (b) 


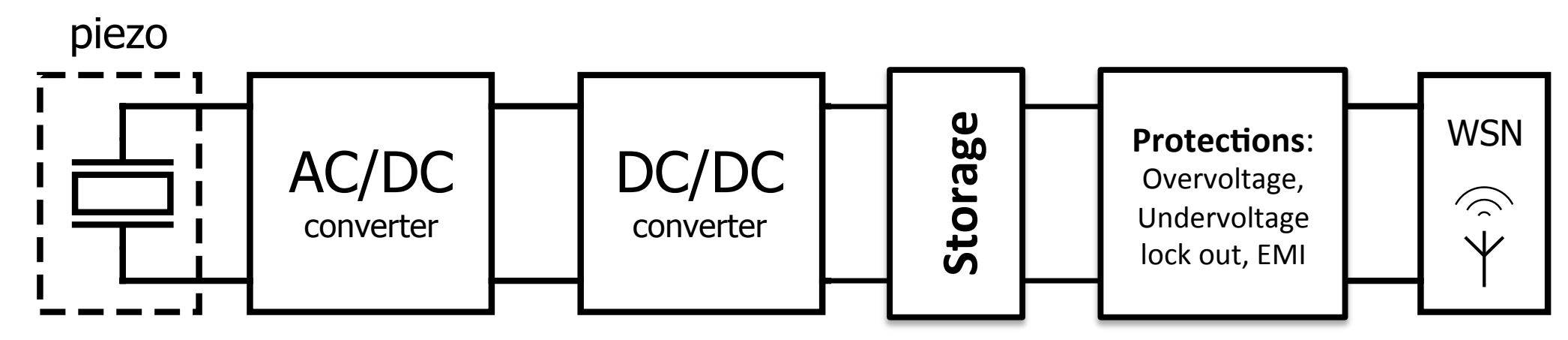

Figure 5 


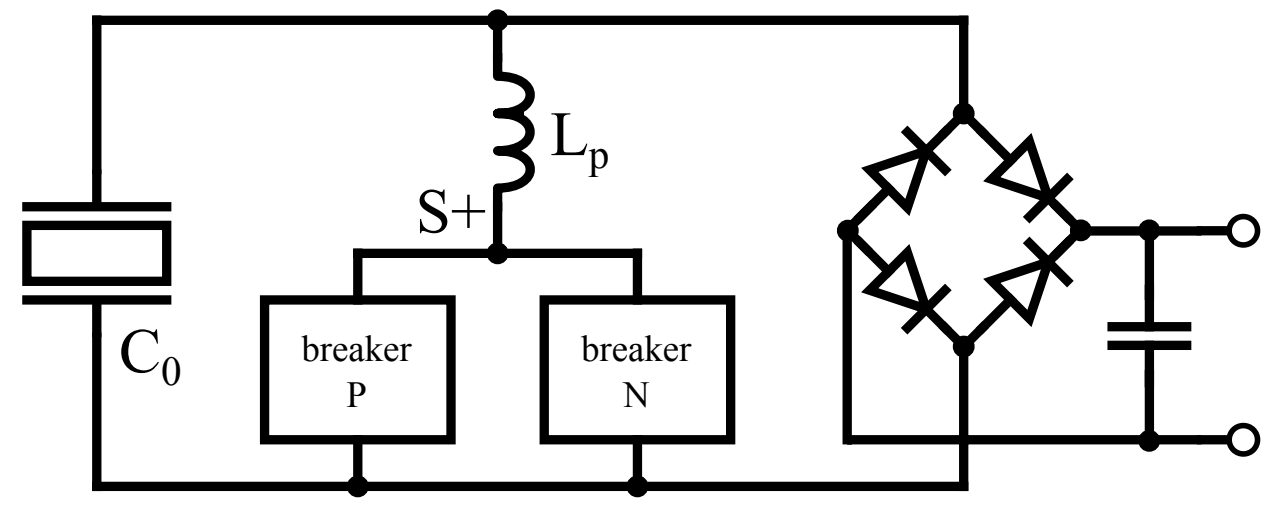

Figure 6 (a) 


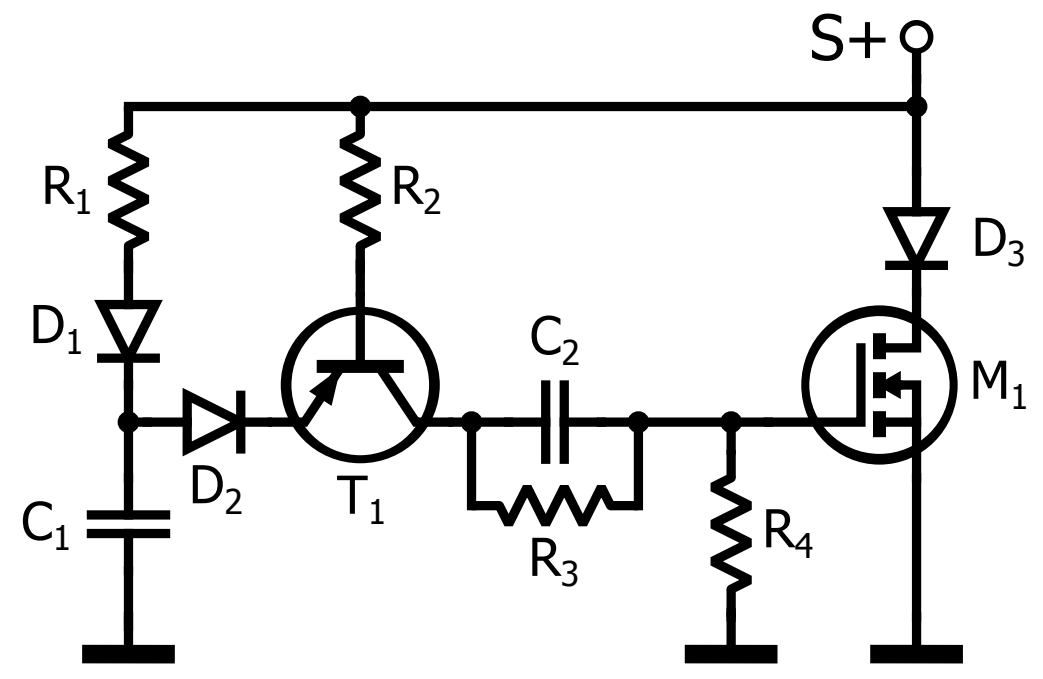

Figure 6 (b) 


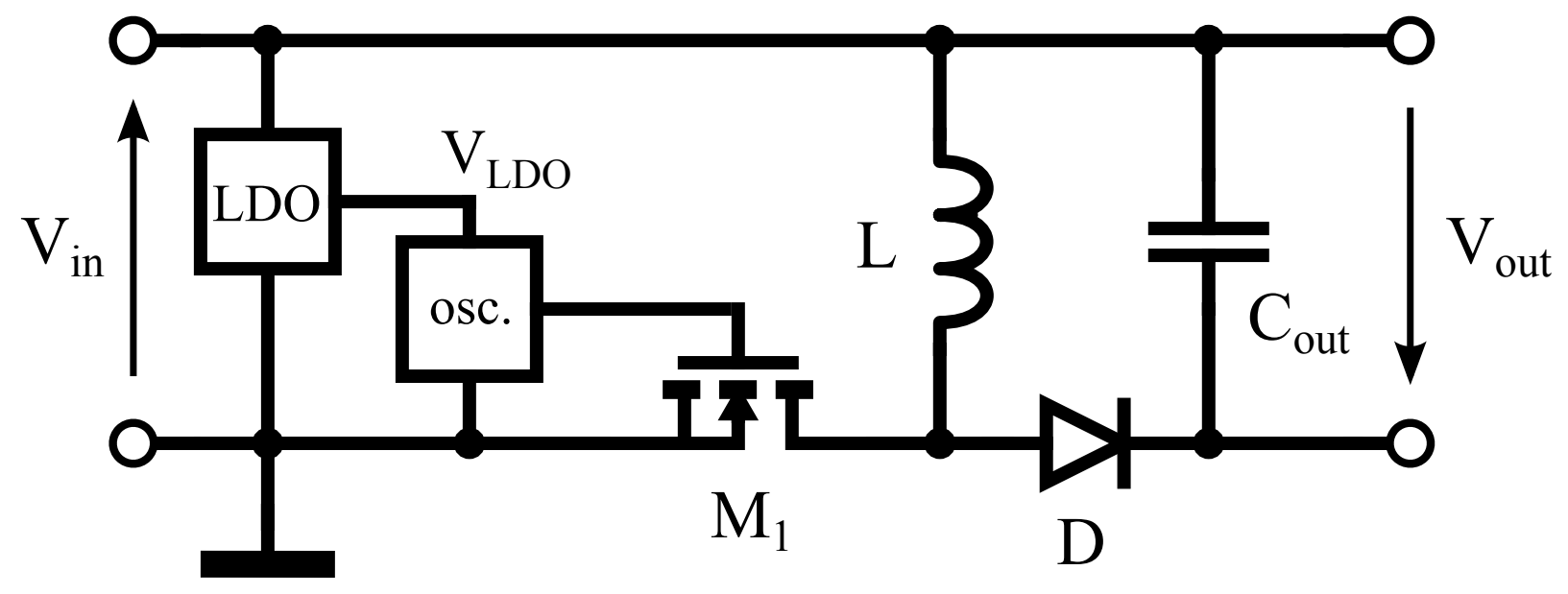

Figure 7 (a) 


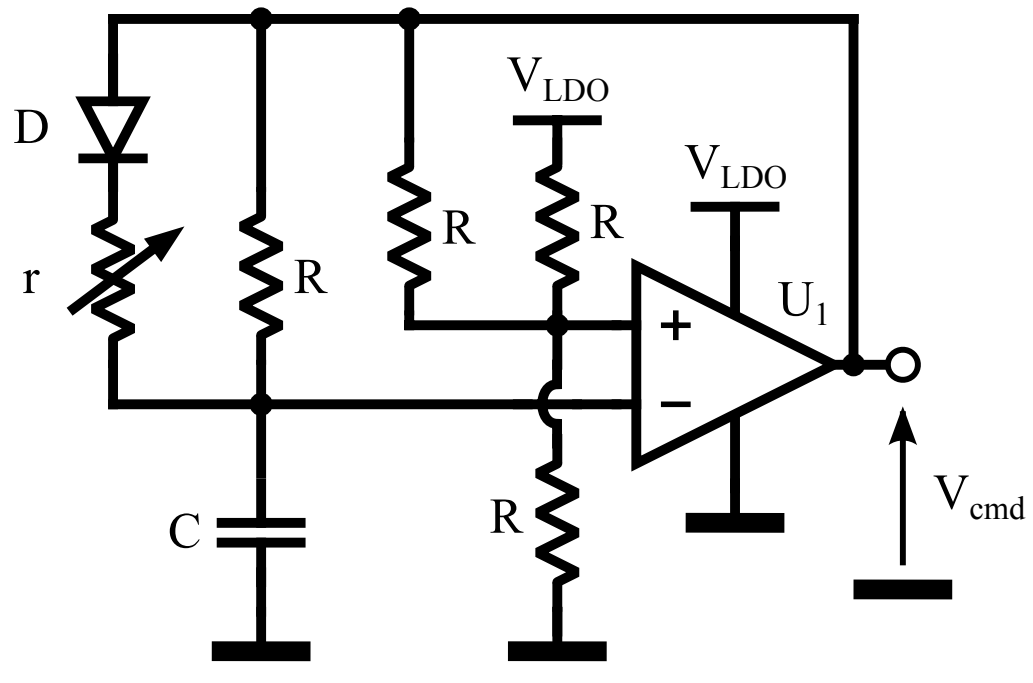

Figure 7 (b) 


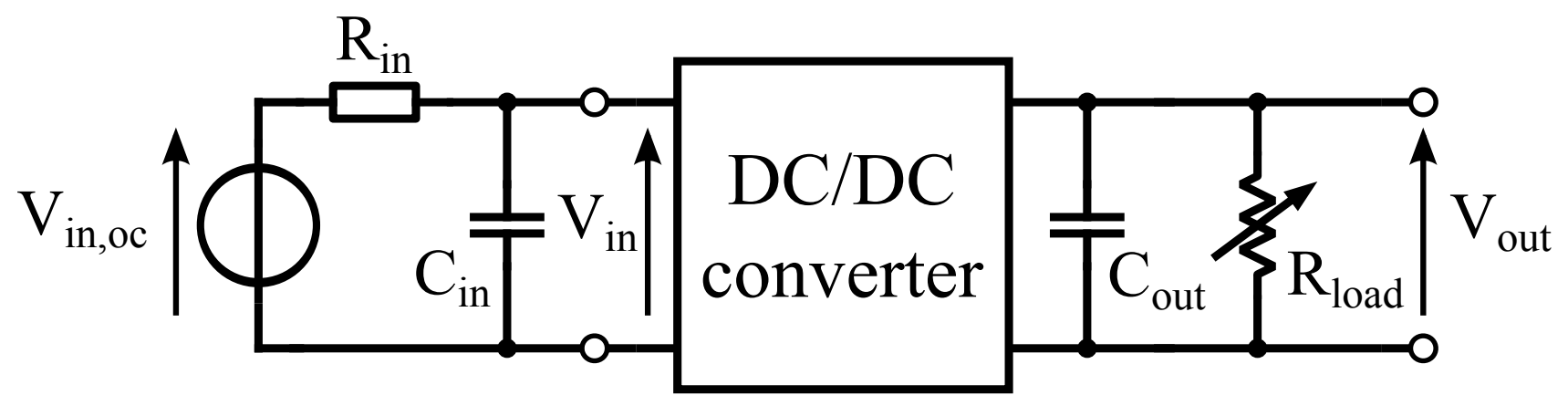

Figure 8 (a) 


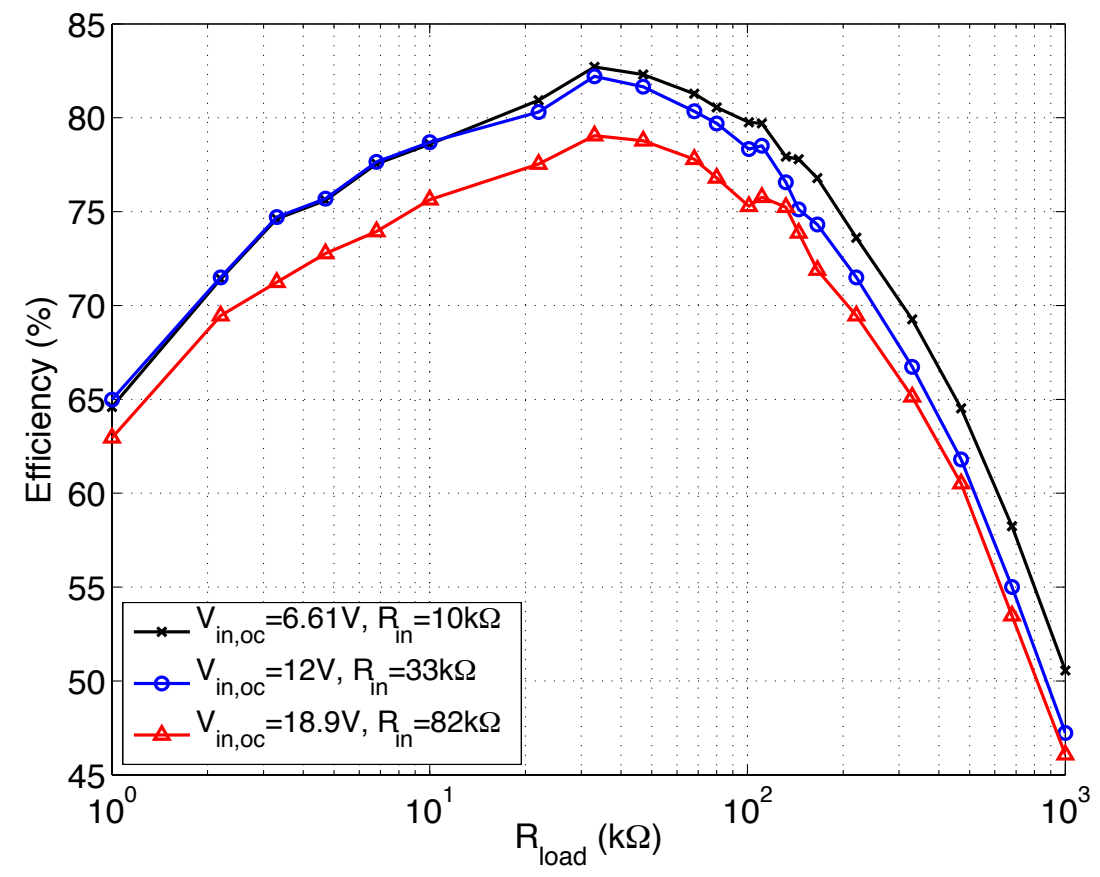

Figure 8 (b) 


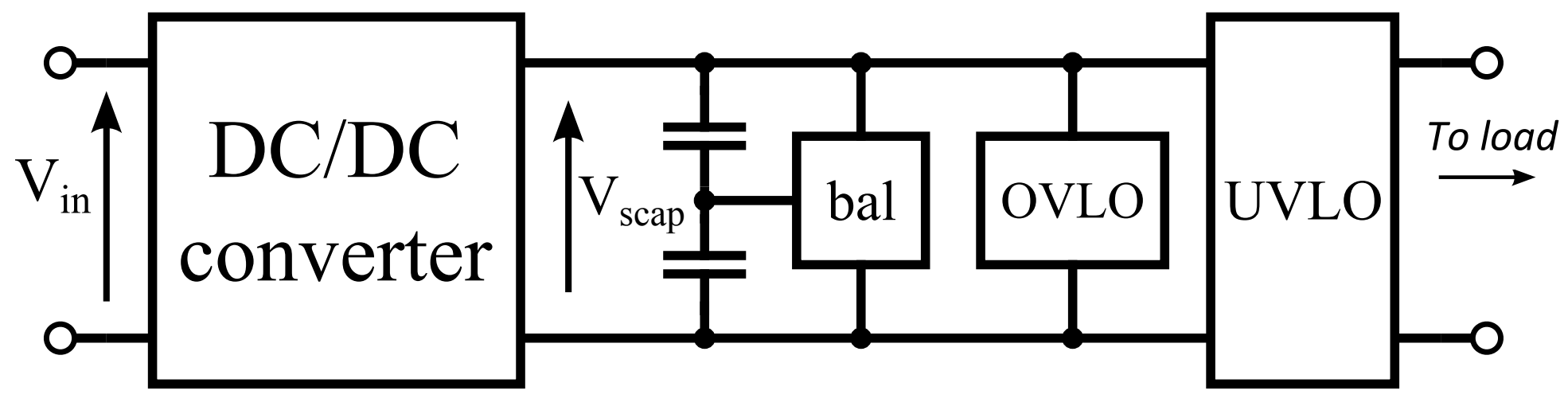

Figure 9 (a) 


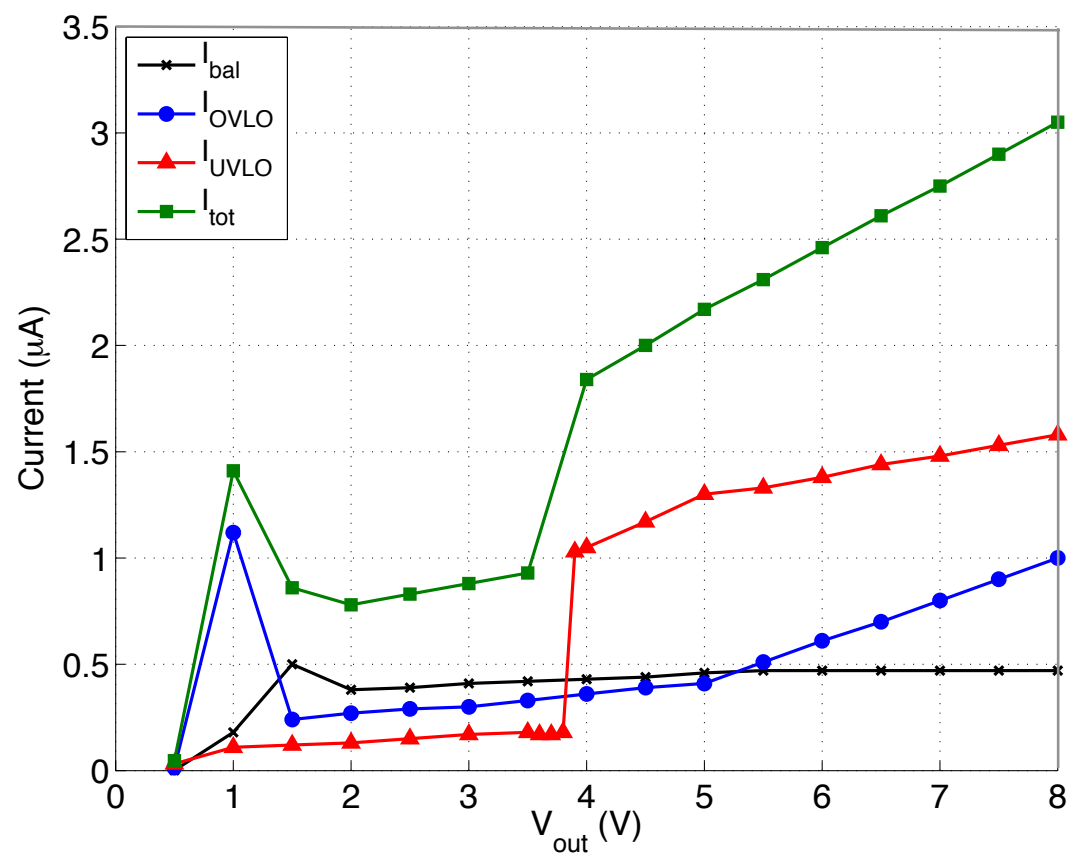

Figure 9 (b) 


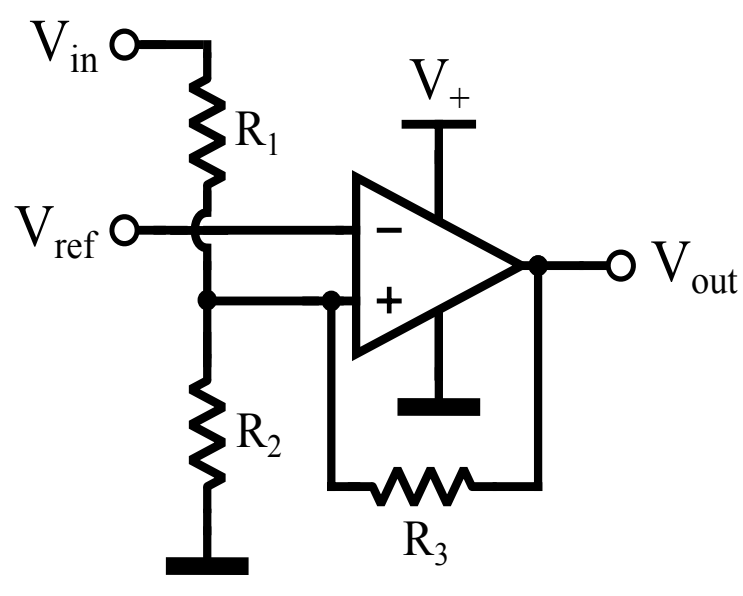

(a)

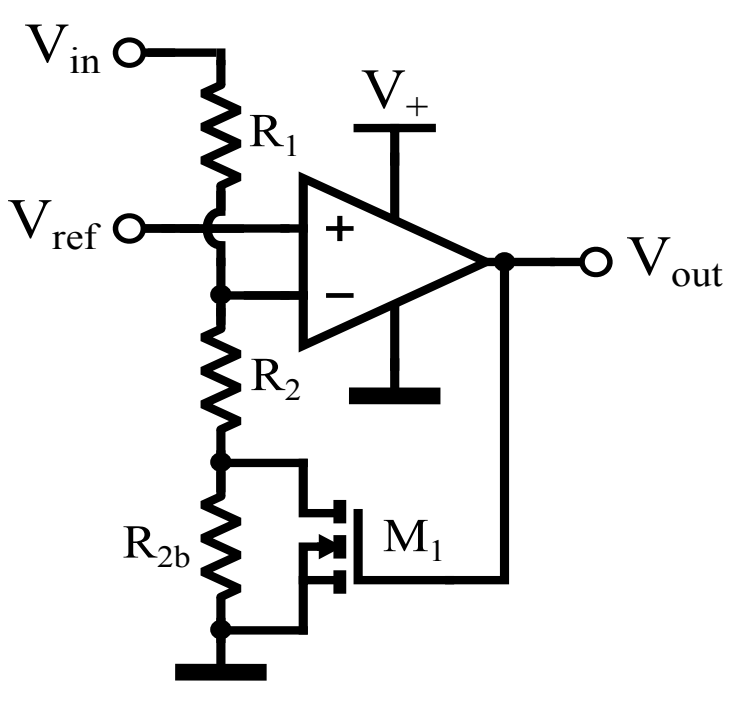

(b)

Figure 10 


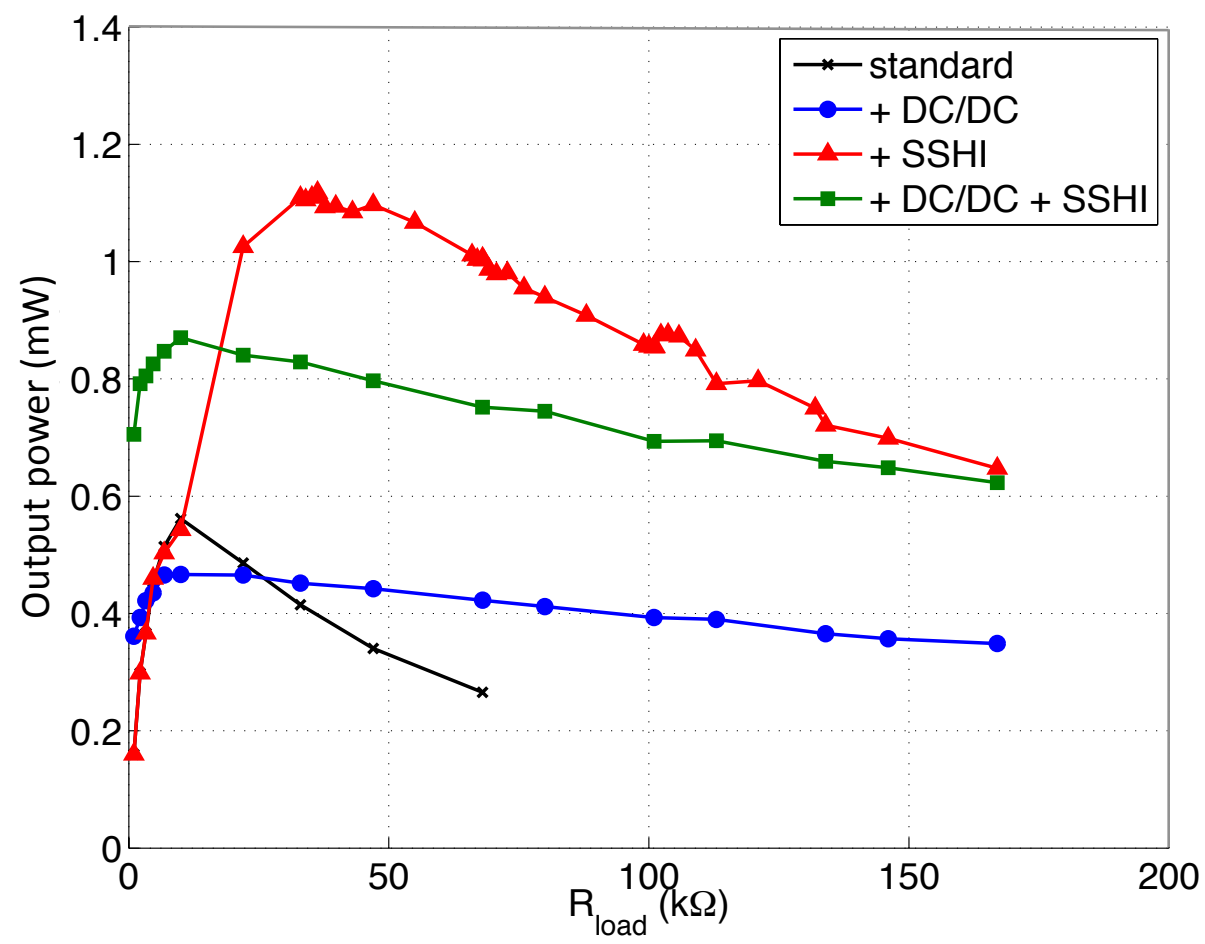

Figure 11 

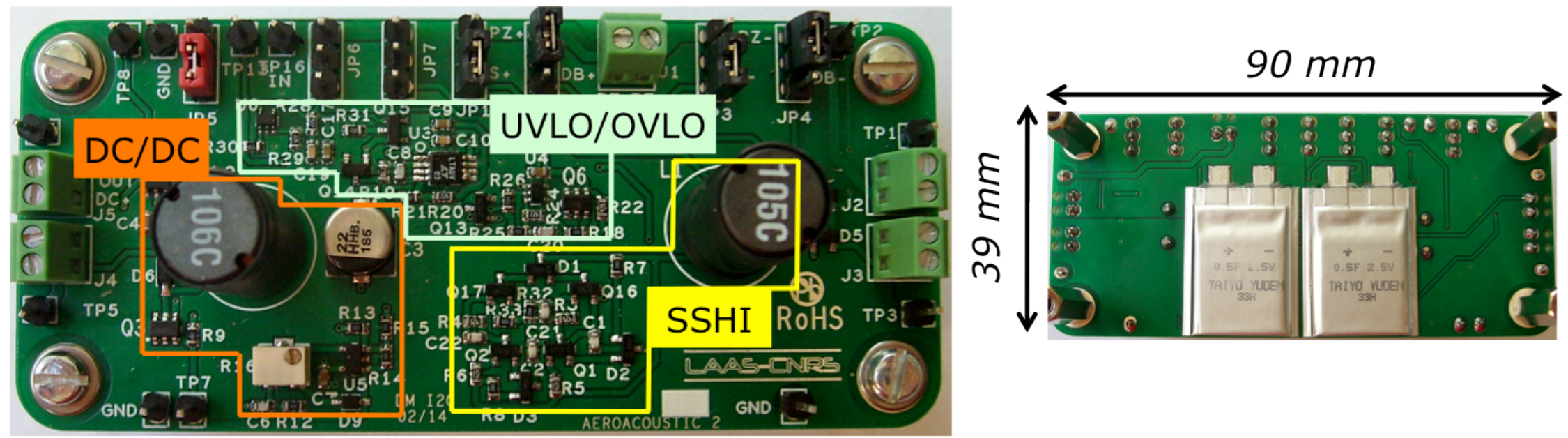

Figure 12 


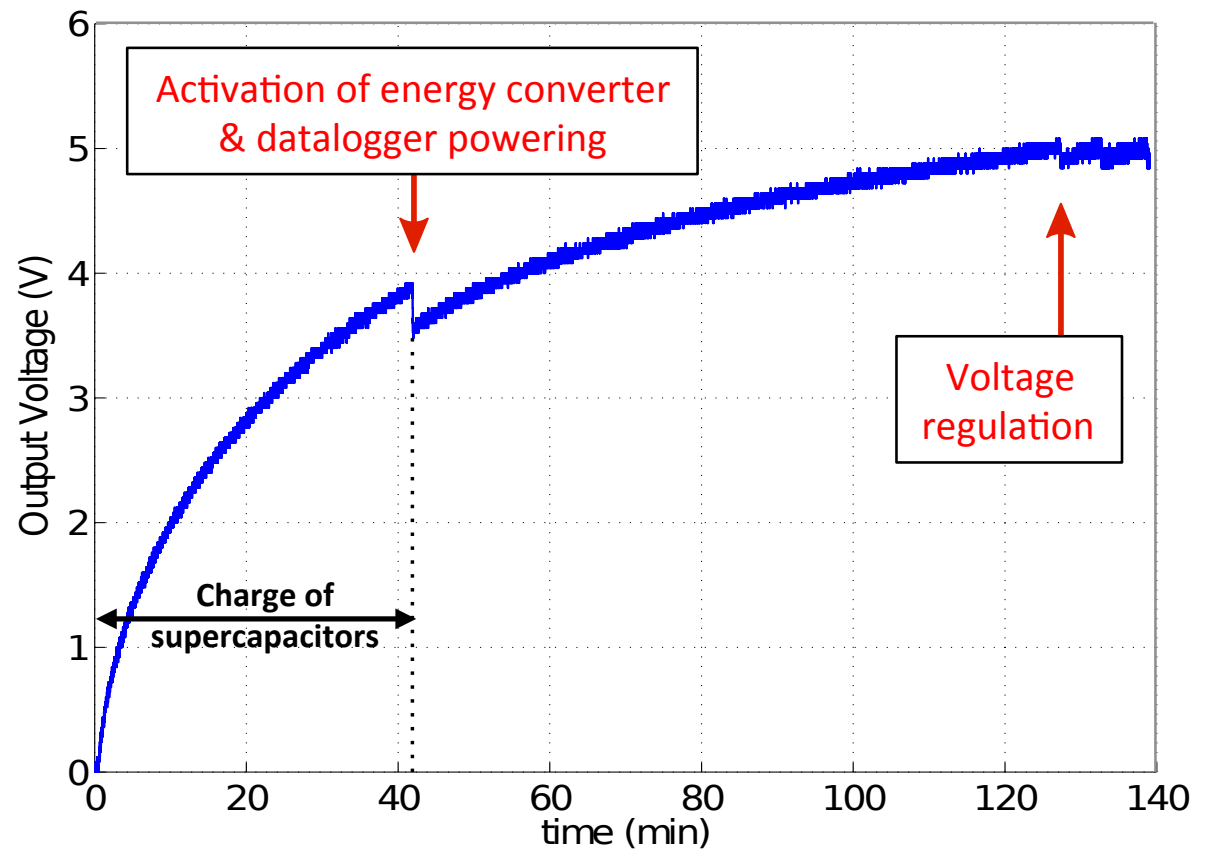

Figure 13 (a) 


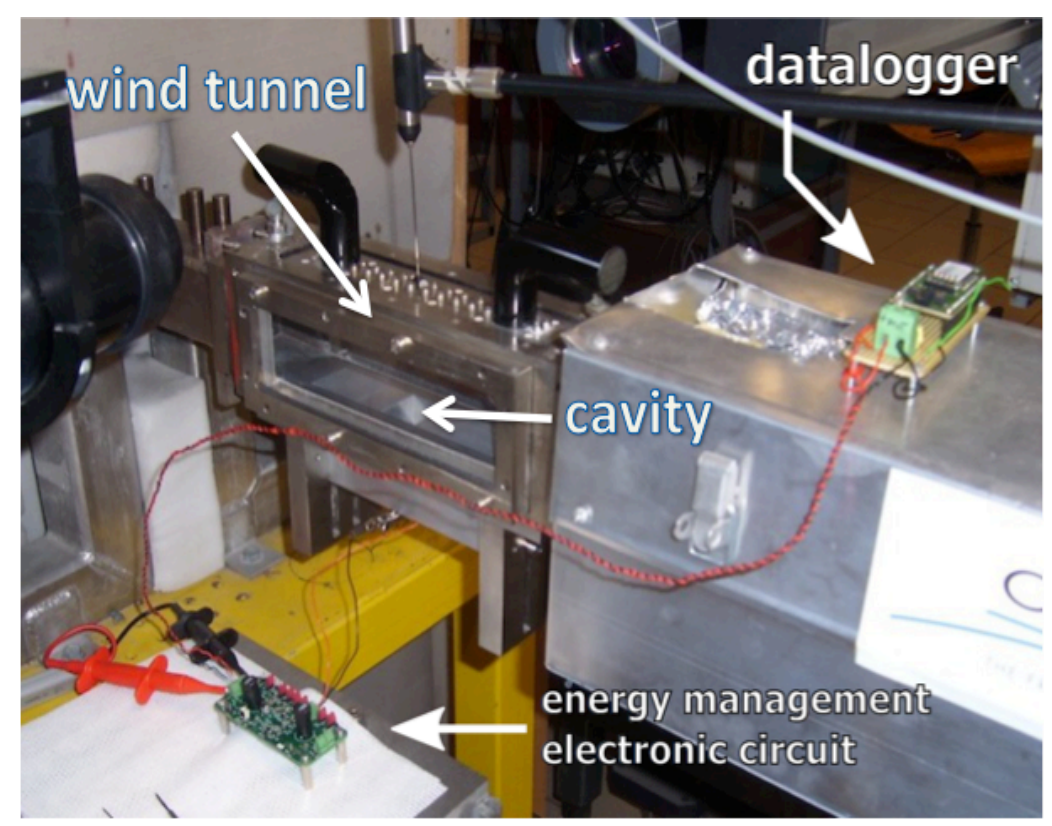

Figure 13 (b) 